\title{
COMPORTAMENTO INGESTIVO E PADRÃO DE DESLOCAMENTO DE BOVINOS EM PASTAGENS TROPICAIS
}

\author{
FEEDING BEHAVIOR AND CATTLE DISPLACEMENT PATTERN \\ IN TROPICAL PASTURES
}

\author{
Teixeira, F.A. ${ }^{1}$, Marques, J.A. ${ }^{2}$, Silva, F.F. ${ }^{3 A}$ e Pires, A.J.V. ${ }^{3 B}$
}

\begin{abstract}
${ }^{1}$ Departamento de Estudos Básicos e Instrumentais. Universidade Estadual do Sudoeste da Bahia. Itapetinga. Brasil. ftxzoo@yahoo.com.br

2Universidade Federal do Recôncavo Baiano. Cruz das Almas. Brasil. jmarques@ufrb.edu.br ${ }^{3}$ Departamento de Tecnologia Rural e Animal Universidade Estadual do Sudoeste da Bahia. Itapetinga. Brasil. Aaureliano@pq.cnpq.br; Bffsilva@pq.cnpq.br
\end{abstract}

\section{PaLAVRAS ChaVE ADICIONAIS}

Bocado. Estação alimentar. Mancha.

\section{RESUMO}

O objetivo desta revisão foi discutir o processo de otimização do pastejo animal, relacionando suas decisões, tomadas em diferentes escalas, aos fatores ligados às características da forragem. O campo e sítio de pastejo podem ser considerados as maiores escalas, onde os fatores bióticos e abióticos (topografia, disponibilidade de água, de abrigos, etc.) se somam influenciando o processo de pastejo, especialmente no sistema de lotação contínua. Outra discussão importante nestas escalas é o número e duração das refeições que os animais perfazem ao longo do tempo em que pastejam, considerando que uma refeição é definida por uma longa seqüência de pastejo. O comportamento dos animais em nível de estação alimentaré um importante indicativo das condições de alimentação, pela sua relação direta com os atributos quantitativos, qualitativos e estruturais do pasto. $\mathrm{O}$ acúmulo de forragem consumida em cada bocado e a freqüência com que os realiza durante o tempo em que passa se alimentando resultam na ingestão total de forragem. Assim, a maximização do consumo, diretamente relacionada à produção do animal, é dependente da maximização de cada bocado desferido em pastejo. Geralmente o manejo adotado afeta a estrutura do pasto influenciando decisivamente o consumo e o comportamento dos animais em pastejo. Desta forma, o processo de pastejo precisa ser controlado dentro dos compartimen-

\author{
AdDitiONAL KEYWORDS \\ Bite. Feeding station. Patch.
}

tos do sistema interface planta-animal, considerando-se que as plantas crescem utilizando energia solar, água e nutrientes fornecidos pelo solo. Porém o crescimento é constantemente influenciado pela ação do animal em pastejo. Embora as relações planta-animal interfiram na decisão do mesmo na busca pelo seu alimento na pastagem, o processo de pastejo, por outro lado, provoca mudanças na estrutura da planta, que por sua vez, promovem um feedback alterando os padrões de deslocamento, busca e apreensão do alimento, padrões de desfolhação de folhas e perfilhos durante o rebaixamento do pasto, Isto funcionaria, como uma forma de tentar compensar reduções nas taxas de consumo.

\section{SUMMARY}

The objective of this review was to discuss the process of optimization of grazing decisions, taken at different scales by the grazing animal, in relation to pasture characteristics. The field, and grazing site, may be considered the largest scales, where biotic and abiotic factors such as topography, water availability, shelters, and others, influence the grazing process, especially in continuous stocking. Another important discussion is the number and duration of meals that animals do during the grazing time, a meal being a long grazing sequence. The behavior of 
the animals at the feeding station are important indicators of the feeding conditions because of its direct relationship with quantity, quality and structure of the pasture. The amount ingested per mouthful, and frequence of biting during grazing time, determine the total pasture intake. Thus, the maximization of consumption, directly related to animal production, is dependent on maximizing every bite fired on grazing. Generally, the management affects the structure of pasture what influences decisively the consumption and behavior of grazing animals, In this way the grazing process needs to be controlled within the compartments of the plant-animal interface, considering that plants grow using solar energy, water and nutrients supplied by the soil. However, its growth is constantly influenced by grazing animals. Although the plant-animal relationships interfer on decisions of animal searching for food in the pasture, the process of grazing, on the other hand, causes structural changes in the plant, which, in turn, affect travel patterns, search and seizure of food, standards of defoliation of leaves and tillers during the grazing. This would function, as a way to compensate for reductions in consumption rates.

\section{INTRODUÇÃO}

As bases para o estabelecimento do manejo de pastagens devem ser alicerçadas não apenas em conhecimentos isolados sobre as plantas forrageiras, solos e nutrição dos animais, sobretudo, o entendimento das relações planta-animal deve ser direcionado no sentido de investigar os processos e a decisão do animal na busca pelo seu alimento na pastagem, considerando as características quantitativas, qualitativas e estruturais da pastagem. Através do comportamento dos animais em pastejo, é possível compreender as características de seu ambiente pastoril, que segundo Carvalho e Moraes (2005) indicam sinais sobre a abundância e qualidade de seu alimento que, se utilizado para ponderar ações de manejo, pode vir a se tornar uma importante ferramenta, além de atender as recentes demandas da sociedade relacionadas ao bem-estar dos animais.
Os animais desenvolveram mecanismos de busca de alimento, derivando estratégias de forrageamento que obtiveram sucesso ao longo do tempo, constituindo o processo de pastejo (Carvalho et al., 1999), que por sua vez se torna um desafio de se ter sua alimentação baseada num recurso que é complexo e dinâmico no tempo e no espaço. No processo de otimização do pastejo, onde o custo de aquisição de forragem é sempre contraditório ao benefício, as decisões de pastejo do animal são tomadas em diferentes escalas. Por definição, a menor escala de decisão do animal é o bocado, que significa a ação ou o ato de apreender a forragem com os dentes (Gibb, 1996) enquanto a estação alimentar é um semicírculo hipotético, disponível em frente ao animal, que ele alcançaria sem mover as suas patas dianteiras (Ruyle e Dwyer, 1985). Um patch é um agregado de estações alimentares separado de outros patches por uma parada na sequência de pastejo, quando o animal se reorientaria para um novo local, ou como uma área onde se observa uma agregação espacial de bocados que se caracterizam por uma taxa de consumo instantânea constante (Bailey et al., 1996; Illius e Gordon, 1999). Um sítio de pastejo representa um agregado de patches em uma área contígua onde os animais pastejariam durante uma refeição. Um campo de pastejo é um agregado de diferentes sítios de pastejo onde os animais buscam água, descanso ou sombra.

Modificações do padrão de pastejo dos animais, induzidas por qualquer característica com dependência de distribuição espacial, podem interferir no desempenho dos animais (ganho de peso, produção de leite, fertilidade, etc.) e na otimização do uso da pastagem (Páscoa e Paranhos da Costa, 2007). Portanto, o processo de pastejo pode ser dividido em uma série de decisões em diferentes escalas de espaço e tempo, ressaltando-se o nível de alimentação, objetivo da criação dos animais e a importância dos parâmetros avaliados em cada escala. Sobretudo, para a determinação do 


\section{INGESTÃO E DESLOCAMENTO DE BOVINOS}

comportamento ingestivo dos ruminantes em pastejo, as metodologias utilizadas devem considerar os aspectos específicos de cada escala e desta maneira representar com maior sensibilidade possível a complexidade das interações onde as variáveis estudadas estão envolvidas. Neste sentido os objetivos desta revisão foram discutir o processo de otimização do pastejo, relacionando as decisões de pastejo do animal, tomadas em diferentes escalas, com os fatores ligados as características da forragem.

\section{CAMPO E SÍTIO DE PASTEJO}

Um sítio de pastejo representa um agregado de patches em uma área contígua onde os animais pastejariam durante uma refeição (definida como uma interrupção da ação de pastejo para descanso, ruminação, etc.). Um campo de pastejo é um agregado de diferentes sítios de pastejo com um foci comum onde os animais buscam água, descanso ou sombra (Bailey et al, 1996). Nesta escala de pastejo, fatores bióticos e abióticos como topografia, disponibilidade de água, de abrigos, dentre outros se somam influenciando o processo de pastejo, especialmente no sistema de lotação contínua. Os animais preferem declividades suaves, inferiores a $60 \%$ e evitam longos deslocamentos horizontais ou verticais em direção a água, menos que $3,2 \mathrm{~km}$. Segundo Launchbaugh e Howery (2005), a qualidade e a quantidade da forragem disponível influenciam a distribuição espacial dos animais e seu desempenho, pois, são atraídos por áreas com elevada concentração de nutrientes, e as memorizam para utilizá-las mais frequentemente. Devido à dificuldade de identificar esses parâmetros, Páscoa e Paranhos da Costa (2007) sugeriram a aplicação dos métodos SIG, poderiam ser utilizados para facilitar o trabalho de pesquisadores, produtores e técnicos, proporcionando uma melhor compreensão das relações entre os diversos fatores envolvidos e gerando informações mais confiáveis para as decisões de manejo. Uma situação discutida nesta escala segundo Carvalho e Moraes (2005) é a lotação excessiva sobre os sítios de pastejo preferenciais, acarretando um superpastejo das espécies preferidas, em pastagens com flora complexa, e algumas espécies de alto valor forrageiro podem desaparecer, entretanto, o superpastejo pode ocorrer ao longo prazo, pela falta de oportunidade de seleção, e não ao excesso dela, resultando em baixos rendimentos zootécnicos em sistema de lotação contínua.

Ítavo et al. (2008) comparando o comportamento ingestivo diurno de bovinos em pastejo contínuo e rotacionado não encontraram efeito do sexo dentro do método de pastejo. Entretanto, os autores verificaram no outono que as médias para o tempo de pastejo foram de 59,8 e 60,7\% para machos e fêmeas, respectivamente para o pastejo contínuo e no método de pastejo rotacionado foram de 44,4 e $44,1 \%$ para machos e fêmeas, respectivamente, atribuindo os valores inferiores para o método de pastejo contínuo à maior competitividade em busca do alimento, pois a taxa de lotação momentânea era maior comparada ao método de pastejo contínuo. Para as atividades de ruminação o método de pastejo rotacionado apresentou maiores médias de tempo gasto para ruminação que os animais do pastejo contínuo. Para as atividades de ócio os animais do método rotacionado, na época do outono, apresentaram maiores médias que os animais do pastejo contínuo, sendo de 27,72 e 29,03\%, os autores explicaram que os animais do pastejo rotacionado permaneceram mais tempo em ócio, pois gastaram menos tempo de suas atividades diurnas com o pastejo.

Outra discussão importante nesta escala é o número e duração das refeições que os animais perfazem ao longo do tempo em que pastejam, considerando que uma refeição é definida por uma longa sequência de pastejo. Em pastejo contínuo são divididas em tur- 
nos, podendo apresentar várias refeições que são interrompidas por intervalos de comprimento variado destinados a outras atividades, como caminhar, descansar ruminar. $\mathrm{O}$ animal responde diretamente à estrutura do pasto, obtendo uma velocidade de ingestão elevada quando a massa de forragem é adequada, enchendo rapidamente o rúmen, quando uma elevada seletividade é permitida, desta forma, os animais têm ciclos rápidos de saciedade, apresentando de acordo com Silveira (2001), refeições que podem durar em torno de 40 minutos, chegando a 6-8 refeições ao longo do dia. Somando-se as refeições e suas durações ao longo do dia tem-se o tempo de pastejo diário, outra variável que indica as condições do pasto. Segundo Carvalho et al. (1999), o tempo de pastejo raramente é inferior a 6 e superior a 12 horas, e sempre concentrado no final da tarde. Interpretando esta variável pode-se afirmar que quanto maior a abundância de forragem, menor o tempo de pastejo observado e as refeições são mais numerosas e com longos intervalos, consequentemente maior o consumo.

Em trabalho com novilhos Manzano et al. (2007) constataram que os tratamentos com maiores intensidades de desfolhação do capim tanzânia em sistema rotacionado diminuiu os tempos de pastejo e de ruminação, enquanto o tempo de ócio aumentou, embora o uso de suplementação energética ou protéica não alterou o tempo de pastejo e ócio, mas diminuiu o tempo de ruminação, em conseqüência do menor consumo de componentes da parede celular (FDN), causado pelo fornecimento do concentrado, e concluíram que a massa seca de forragem disponível na pastagem exerce efeito mais acentuado sobre o comportamento ingestivo de bovinos em pastejo que a prática de suplementação. Bremm et al. (2008), trabalhando com novilhas de corte submetidas a estratégias de suplementação em pastagens de aveia e azevém, verificaram que o tempo de pastejo dos animais foi maior quando passaram a receber $0,6 \%$ do
$\mathrm{PV}$ de suplemento, relacionando às maiores proporções de lâminas foliares no pasto, principalmente de aveia.

Brâncio et al. (2003) verificaram que nenhuma característica quantitativa da pastagem foi correlacionada com o tempo de pastejo, contrariando os dados da literatura, a disponibilidade e a altura não foram correlacionadas com o tempo de pastejo (Penning et al., 1991), enquanto as características qualitativas, no início da ocupação dos piquetes, apenas o teor de lignina da forragem foi correlacionado e no final do período de ocupação dos piquetes, o valor nutritivo da forragem pareceu ter mais influência, verificando-se correlações negativas entre o tempo de pastejo e o teor de proteína bruta e entre o tempo de pastejo e a digestibilidade, que pode ser atribuído ao fato dos animais necessitarem de mais tempo, quando a forragem é de baixo valor nutritivo, para satisfazer seus requerimentos em nutrientes, principalmente se os tamanhos de bocado forem reduzidos.

Olivo et al. (2008) avaliando o comportamento ingestivo de vacas em lactação sob diferentes sistemas forrageiros, observou que o tempo médio de pastejo foi significativamente maior no sistema forrageiro composto de capim elefante em consórcio com trevo-branco, azevém e espécies de crescimento espontâneo, nos quais a disponibilidade de lâminas foliares do capimelefante interferiu diretamente, enquanto os tempos de ruminação e ócio foram similares, tanto entre os ciclos de pastejo quanto entre os sistemas forrageiros avaliados.

\section{ESTAÇÃO ALIMENTARE PATCH}

Recentemente um patch tem sido definido como uma área onde se observa uma agregação espacial de bocados que se caracterizam por uma taxa de consumo5 instantânea constante (Illius e Gordon, 1999). A forma com que os animais exploram as estações alimentares determina seu nível de consumo, uma vez que as regras de 


\section{INGESTÃO E DESLOCAMENTO DE BOVINOS}

escolha e de abandono das mesmas afetam a ingestão de forragem e a eficiência do processo de pastejo (Carvalho e Moraes, 2005). O processo de pastejo, sendo regido pelos mecanismos e estratégias dos animais, é de suma importância porque em pastejo há uma necessidade nutricional a ser atendida e uma limitação de tempo para satisfazê-la. Gasto excessivo de tempo em determinado processo pode acarretar restrição de consumo e o não atendimento da demanda diária, pois o animal, além de pastejar, deve utilizar parte do tempo para ruminar o alimento que consumiu e para descansar e realizar atividades sociais (Rook e Penning, 1991).

O comportamento dos animais em nível de estação alimentar é um importante indicativo das condições de alimentação, pela sua relação direta com os atributos quantitativos, qualitativos e estruturais do pasto. Durante o pastejo, toda vez que o animal tem suas patas dianteiras imóveis, e inicia a remoção da forragem que está a sua frente, estabelece-se uma área denominada estação alimentar (Ruyle e Dwyer, 1985). Ao início da exploração de uma estação alimentar, o animal se defronta com escolhas como, por exemplo, quais tipos ou partes de uma planta colher, essas estratégias são fundamentais na definição do consumo em pastejo. Como descrito por Carvalho et al. (1999), o tempo de permanência na estação alimentar está relacionado à sua abundância de forragem, ou seja, quanto maior a oferta de forragem na estação alimentar, maior o tempo de permanência dos animais nela até que o ponto de abandono seja atingido, quando a relação custo-benefício em explorá-la passa a ser menos interessante. Baggio et al. (2009) confirmaram esta afirmação, pois, o aumento na massa de material senescente influenciou a diminuição do número de bocado por estação alimentar, trazendo dificuldade na seleção da dieta dentro de uma mesma estação alimentar nos pastos de maior altura, considerando que as lâminas foliares encontraram entremeadas na grande quantidade de material morto, resultando em maior intervalo de tempo de um bocado a outro.

Em pastos com maior disponibilidade de forragem observa-se um elevado tempo de permanência, ou seja, número reduzido de estações alimentares, num mesmo intervalo de tempo, assim, como número de passos entre estações é alto, na medida em que o animal colhe uma massa de bocado elevada na última estação anterior, permite a ele caminhar entre estações por mais tempo enquanto mastiga. Já numa oferta de forragem baixa, os animais tendem a apresentar deslocamentos curtos e retilíneos e o número de passos entre estações é pequeno, refletindo a pouca massa de bocado colhida no último bocado da estação anterior. Adicionalmente, Carvalho et al. (1999) afirmaram que o animal pode ser mais seletivo sem perder a eficiência no deslocamento, pois este procura a próxima estação mastigando o último bocado, otimizando seu tempo. Além disso, outra estratégia que os animais usam em condições de abundância de forragem de acordo com Carvalho e Moraes (2005) é aumentar o ângulo de deslocamento, aumentando assim a taxa de encontros com estações de elevada massa, utilizando melhor o patch de alta qualidade.

Baggio et al. (2009) trabalhando com pastagem de azevém-anual e aveia-preta em sistema de integração lavoura-pecuária, verificaram aumento linear do tempo de permanência na estação alimentar com o aumento da altura do pasto no estádio vegetativo, apresentando correlação positiva com a oferta de lâminas foliares, o tempo de permanência na estação alimentar, que por sua vez está diretamente relacionado à abundância de forragem (Carvalho et al., 1999). Estes autores observaram que o deslocamento entre estações alimentares foi maior em situação de abundância de forragem, em função da colheita de bocados com alta quantidade de forragem, assim como os animais procuram ser eficientes e não se deslocam se não estiverem 
executando qualquer atividade, portanto, quanto maior o último bolo colhido a ser mastigado, maior o tempo para escolha $\mathrm{e}$ deslocamento. Baggio et al. (2008) demonstraram que, com a diminuição da altura do pasto, aumenta o tempo de pastejo, que varia de 459 a $380 \pm 37,1$ minutos, respectivamente, para as alturas de 10 e $40 \mathrm{~cm}$.

De acordo com os estudos de Palhano et al. (2006), os padrões de deslocamento e procura de forragem de novilhas leiteiras foram alterados pela estrutura do dossel, embora em situações de menor oferta de forragem, os animais apresentam estratégias alimentares compensatórias, visando aumentar a taxa de ingestão de forragem. Por outro lado, a intensidade de utilização da área diminui com o incremento em altura do dossel, visto que a elevação da massa de forragem disponível nas maiores alturas do dossel não os motiva à procura por outros sítios de pastejo. Trabalhando com comportamento ingestivo de bovinos e ovinos Gonçalves (2007) também verificou que os padrões de deslocamento foram afetados pela estrutura do campo nativo, concluindo que na altura do pasto compreendida entre 8 e $12 \mathrm{~cm}$, os animais permaneceram mais tempo pastejando nas estações alimentares e percorreram distâncias maiores à procura de novos locais de pastejo.

Baggio et al. (2009) inferiram que com a diminuição da massa de lâminas foliares, houve aumento no número total de estações alimentares, que está relacionado ao menor tempo de permanência, bem como à menor movimentação entre estações alimentares sucessivas. As estações alimentares com baixa oferta de forragem rapidamente atingem o ponto de abandono e os animais se deslocam para estabelecerem nova estação alimentar (Carvalho e Moraes, 2005), desta forma os animais precisam aumentar o número total de estações alimentares diárias a fim de manter a taxa de consumo de forragem. Quanto ao deslocamento dos animais na pastagem, Baggio et al. (2009) constataram correlação com a massa de lâminas foliares, demonstrando aumento do número total de passos com a diminuição desse componente do pasto. Em situações de estrutura do pasto não-limitante, o deslocamento entre estações alimentares pode ser mais longo, porém, a quantidade de deslocamento total é menor que em situações limitantes de forragem disponível (Carvalho e Moraes, 2005). O consequente aumento da taxa de consumo certamente permite ao animal alocar mais tempo na procura de estações alimentares preferidas, enquanto caminham maiores distâncias mastigando bocados maiores, apesar do aumento na distância percorrida entre estações alimentares com o aumento da altura do pasto, isto resulta, segundo Palhano et al. (2006) que os animais apresentaram menor deslocamento total.

Com a redução da oferta de forragem durante o rebaixamento do pasto e como forma de compensar o maior gasto energético despendido pelo maior deslocamento e tempo de procura, caracterizada por uma maior quantidade de passos entre estações e maior número de estações alimentares exploradas, Trindade (2007) deduziu que os animais, ao encontrarem o componente folha, desferiram desfolhas mais intensas. Da mesma forma, ao longo do rebaixamento, os animais, com intuito de consumir forragem com maior proporção de folhas que de colmos e material morto, aumentaram a intensidade de desfolhação das folhas e diminuíram a profundidade de desfolhação dos perfilhos. Entretanto, quando o autor analisou as repostas da taxa de consumo e composição da extrusa, julgou que essas estratégias dos animais foram fortemente limitadas pela estrutura do pasto, a qual foi modificada por eles mesmos ao longo do processo de rebaixamento.

Teixeira (2010) avaliando o padrão de deslocamento em pastagens de Brachiaria decumbens diferida sob diferentes estratégias de adubação nitrogenada, constatou que o número de estações 


\section{INGESTÃO E DESLOCAMENTO DE BOVINOS}

alimentares por minuto foi maior $(\mathrm{p}<0,05)$ para os pastos cuja estratégia de adubação, foi a aplicação de $100 \mathrm{~kg} \cdot \mathrm{ha}^{-1}$ de $\mathrm{N}$ no final do verão (figura 1). Embora constatada maiores quantidade de estações alimentares visitadas num determinado espaço de tempo, pode-se inferir que os animais tenham decidido escolher novos patch próximos, considerando a alta disponibilidade de matéria seca de forragem encontrada em todos os pastos. $\mathrm{O}$ autor inferiu que a distribuição espacial da forragem em pastos diferidos com maior índice de tombamento, tenha dificultado a seleção de forragem obrigando o animal a procurar por outra estação alimentar. Os resultados corroboraram com os relatos de Griffiths et al. (2003), pois, mais que a massa de forragem disponível, a estrutura vertical, correspondente ao que foi consumido dentro da estação de "cima para baixo", é que determinaria o tempo de permanência do animal em cada estação alimentar.

\section{NÍVEL DE BOCADO}

A menor escala de decisão do animal é o bocado, que significa a ação ou o ato de apreender a forragem com os dentes (Gibb, 1996). Na medida em que o consumo se constitui num somatório de cada ação de captura de forragem pelo bocado, a maximização do consumo, está diretamente relacionada à magnitude da produção animal, passa necessariamente pela maximização de cada bocado desferido em pastejo. A apreensão de forragem por meio do bocado é um processo que não raro pode atingir 35.000 ações diárias, onde os animais freqüentemente pastejam ao ritmo de um bocado a cada 1-2 segundos (Carvalho et $a l ., 2001)$. Todo e qualquer procedimento de manejo que torne o processo de aquisição de forragem mais rápido seria de suma importância. O manejo de pastagens deve ser visto como a construção de estruturas de pasto que otimizem a colheita de forragem

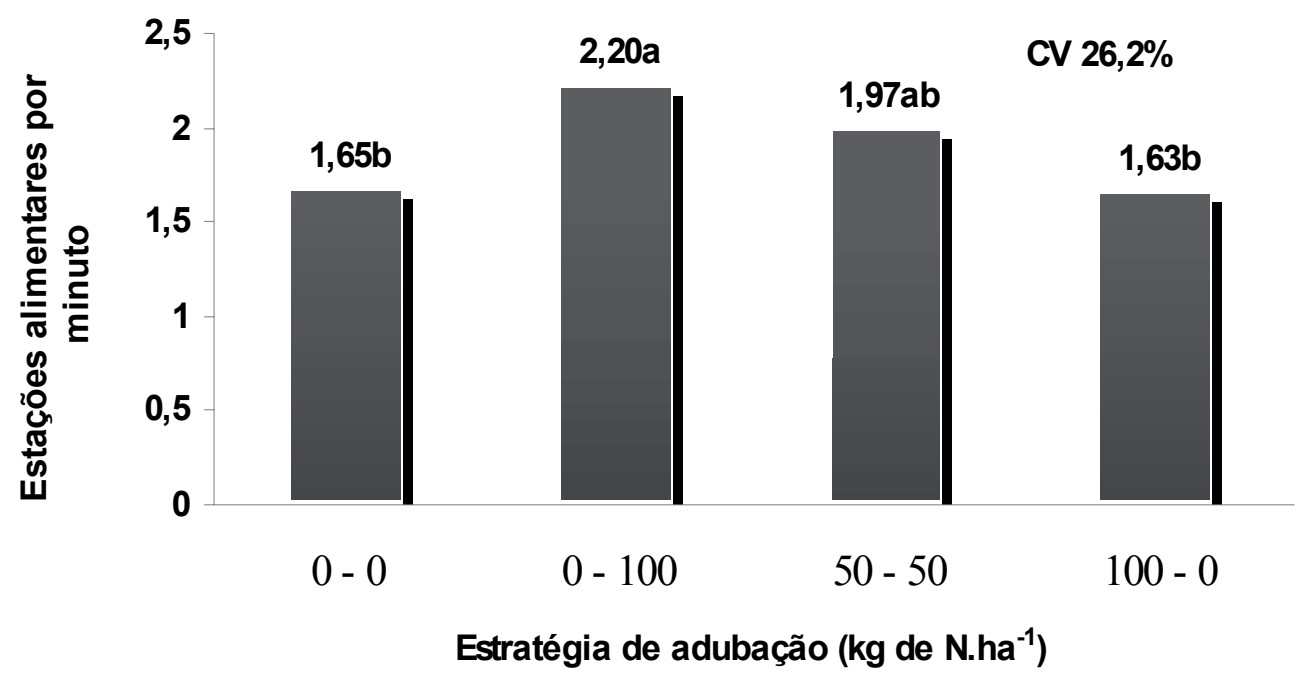

Figura 1. Número de estações alimentares por minuto de novilhos em pastos de B. decumbens diferidos, sob quatro estratégias de adubação nitrogenada (Teixeira, 2010). (Number of feeding stations per minute for steers grazing pasture of $B$. decumbens submited to four levels of $N$ (Teixeira, 2010)). 
pelo animal em pastejo (Carvalho et al., 2001, Silva e Carvalho, 2005).

A profundidade do bocado responde de forma linear e positiva ao incremento na altura de manejo do pasto. Bocados que conseguem colher uma elevada massa imprimem maior velocidade de ingestão até o ponto onde a massa do bocado atinge o seu ponto de máxima. Já em pastagens nativas com flora complexa (Gonçalves et al., 2009), como as pastagens tropicais, o ponto de otimização para novilhas ocorre em $11,4 \mathrm{~cm}$ indicando as intrincadas possibilidades de metas de estrutura segundo os mais variados tipos de recurso forrageiro. Enquanto a massa do bocado responde de forma positiva ao incremento na altura do pasto, a taxa de bocados apresenta-se inversa e negativamente relacionada à sua abundância (Carvalho et al., 1999). O aumento da massa do bocado produz um aumento dos requerimentos de mastigação e manipulação da forragem capturada, reações essas necessárias à deglutição do bolo apreendido. Portanto, os animais alocam os movimentos de apreensão, manipulação e mastigação conforme a massa do bocado que capturam. Esses movimentos são, pois, competidores entre si, e não compensatórios (Carvalho et al., 2001). Com isto, e devido à relação inversa entre a massa do bocado e a taxa de bocados, a velocidade de ingestão pode variar entre 2 e 3 vezes segundo a estrutura que o animal esteja pastejando. A ingestão total é o resultado do acúmulo de forragem consumida em cada bocado, na menor escala do processo de pastejo, e da freqüência com que os realiza durante o tempo em que passa se alimentando, assim, a maximização do consumo, diretamente relacionada a produção do animal, é dependente da maximização de cada bocado desferido em pastejo (Carvalho e Moraes, 2005). Segundo Carvalho et al. (2001) a apreensão de forragem por meio do bocado pode atingir em torno de 35.000 ações diárias, com os animais frequentemente realizando $30-70$ bocados por minuto, ao ritmo de um bocado a cada 1-2 segundos

A altura ideal do relvado é uma variável que deve ser considerada em função da profundidade sobre a área do bocado na construção da massa do bocado, que de acordo com Carvalho et al. (2001) e Silva e Carvalho (2005) é reconhecida como a principal determinante da velocidade de ingestão por animais em pastejo. Uma forma de medição da profundidade de bocados é por meio da técnica de perfilhos estendidos marcados no pasto que normalmente ocorre a $50 \%$ da altura do perfilho. Embora a massa do bocado responda ao aumento na altura do pasto, a taxa de bocados é apresentada de forma contrária à abundância de forragem, pois o aumento da massa do bocado causa aumento da mastigação e manipulação da forragem, portanto, os animais distribuem os movimentos de apreensão, manipulação e mastigação conforme a massa do bocado, sendo eles competidores entre si, e não compensatórios (Carvalho et al., 2001).

Brâncio et al. (2003) encontraram redução nos tamanhos de bocado, no período seco, o que poderia ter limitado o consumo total de forragem pelos animais nesta época. Embora tenham modificado o padrão de distribuição do tempo de pastejo ao longo do dia nas diferentes épocas, mas o tempo de pastejo total diário pouco variou, entretanto, verificou que as mudanças ocorridas no pasto ao longo do período de ocupação do piquete foram desfavoráveis a seleção da forragem preferida, uma vez que houve redução dos tamanhos dos bocados e aumento do tempo de pastejo e da taxa de bocados.

Segundo Rego et al. (2006), uma das estratégias utilizadas pelo animal quando ocorre redução na ingestão por bocado, decorrente das condições desfavoráveis da pastagem (redução na altura e proporção de folhas e aumento da proporção de hastes e de material morto), é aumentar a taxa de bocados (bocados por minuto) ou, de forma 


\section{INGESTÃO E DESLOCAMENTO DE BOVINOS}

análoga, mudanças positivas na estrutura da pastagem podem resultar em aumento na ingestão por bocado e na diminuição da taxa de bocados, esperando-se que maiores valores de ingestão por bocado resultem em maior tempo por bocado (Hodgson, 1990). O tempo por bocado depende da facilidade de apreensão e mastigação, influenciada pelas características estruturais da pastagem e pelo teor de fibra da planta (Roguet et al., 1998). Entretanto, deve-se ressaltar que a estratégia de aumentar a taxa de bocados para maximizar a taxa de ingestão implica maior gasto de energia por unidade de MS consumida. Provavelmente, acréscimos na ingestão por bocado sejam mais interessantes para o animal, em razão do menor custo energético por unidade de MS ingerida. Estudos têm comprovado que o aumento no número de bocados geralmente não compensa a redução no peso do bocado (Ungar et al., 1991) para manter elevados os valores de taxa de ingestão. Portanto, o tempo de manipulação do bocado é uma característica dependente das características estruturais e qualitativas da planta (Prache e Peyraud, 1997).

Hodgson (1990) e Flores et al. (1993) verificaram que a elevação na altura da pastagem proporcionou incrementos na taxa de ingestão das pastagens avaliadas, provavelmente em razão dos efeitos positivos na profundidade de pastejo. Rego et al. (2006) confirmaram este achado concluindo que a taxa de ingestão instantânea pelos animais nas pastagens tropicais exclusivas e na consorciação é intensificada pela altura da pastagem, no entanto, as características do bocado são influenciadas pelas diferentes estruturas da pastagem, verificando que a estrutura da leguminosa exclusiva proporciona aumento na taxa de bocados e diminuição no tempo de manipulação do bocado, enquanto as gramíneas tropicais exclusivas e a consorciação favorecem o aumento na ingestão por bocado.

Baggio et al. (2009) trabalhando com pastagem de azevém-anual e aveia-preta em sistema de integração lavoura-pecuária, verificaram que com o aumento das alturas de manejo, os animais reduziram a taxa de bocado, pois normalmente esta variável apresenta-se inversa e negativamente relacionada à abundância de pasto, certamente o aumento da quantidade de forragem disponível e da massa do bocado que determina maior exigência dos processos de mastigação e de manipulação da forragem capturada, levou a maior intervalo de bocados. Este aumento seria resultado do esforço na colheita de menor quantidade de folhas disponíveis nos perfilhos reprodutivos, uma vez que as folhas, além de estarem em mais baixa disponibilidade, se encontram distanciadas pelo aumento dos entrenós dos colmos, dificultando sua captura (Carvalho et al., 2001). Baggio et al. (2009) constataram que a redução da quantidade de massa de forragem, associada à diminuição da altura do pasto, resultou em aumento no número total de bocado, fato que está diretamente relacionado à estrutura do pasto, como também a massa do bocado, ou seja, quanto menor a altura do pasto, menos efetiva é a capacidade dos animais em ampliar a quantidade de forragem apreendida, assim os animais necessitam aumentar o tempo de pastejo, a taxa de bocado, o número de bocado por estação alimentar e o número de bocado diário para compensar a menor massa apreendida por bocado e manter níveis de consumo satisfatórios.

Carvalho et al. (2001) constatou que a profundidade do bocado é a variável que mais responde às variações na altura do dossel forrageiro, o que indica ser a variável determinante do volume do bocado. Com o exemplo das escalas de pastejo discutidas é possível inferir sobre a qualidade do ambiente de pastejo pela observação do comportamento ingestivo dos animais, assim, quando a taxa de bocados é elevada, a possibilidade de limitação de ingestão e desconforto em pastejo é concreta, indicando que dificilmente os animais atingirão o nível de saciedade. 


\section{FATORES LIGADOS A FORRAGEM}

O manejo geralmente adotado afeta a estrutura do pasto afetando decisivamente o consumo e o comportamento dos animais em pastejo, assim, o processo de pastejo precisa ser controlado dentro dos compartimentos do sistema interface plantaanimal, considerando que as plantas crescem utilizando energia solar, água e nutrientes fornecidos pelo solo, enquanto o seu crescimento é constantemente influenciado pela ação do animal em pastejo, pela remoção de folhas, seletividade, pisoteio e deposição de excrementos acarretando a modificação constante do ambiente de pastejo. A mensuração das características estruturais do pasto é de fundamental importância para melhorar o entendimento da relação plantaanimal (Roman et al., 2008), pois o animal responde a variações na estrutura do pasto (Carvalho et al., 2007; Benvenutti et al., 2008) especialmente em pastagens tropicais.

Sbrissia et al. (2003) e Sbrissia (2004) demonstraram que quanto maior a altura de manejo de pastos de Tifton-85 (Cynodon sp.) e de capim marandu (Brachiaria brizantha cv. Marandu), respectivamente, menor é a densidade populacional de perfilhos e estes são maiores comparativamente a condições de alturas de manejo mais baixas. Hodgson (1990) comprovou que sob lotação contínua os perfilhos normalmente são menores e a densidade populacional maior, enquanto que em pastos sob pastejo rotacionado, na condição de pré-pastejo, os perfilhos são maiores e a densidade populacional menor, resultado do mecanismo de compensação tamanho densidade populacional de perfilhos, como resposta das plantas à frequência e intensidade de desfolhação a que são submetidas, alterando sua arquitetura. Sob lotação contínua, as desfolhações ocorrem de maneira mais frequente obrigando as plantas de tornarem-se mais resistentes ao pastejo, diminuindo a chance de serem desfolhadas (escape), enquanto sob pastejo intermitente, os perfilhos respondem à competição por luz no interior do dossel, ou seja, se desenvolvem buscando o topo do dossel e acesso à luz incidente, fazendo com que a relação folha:colmo diminua como conseqüência da alocação de carbono em estruturas de sustentação (Bullock, 1996).

Trindade (2007) trabalhando com capim marandu submetido a estratégias de pastejo rotacionado verificou que as variações estruturais causadas no dossel afetaram o comportamento ingestivo dos animais, baseadas em alteração dos padrões de busca e de utilização das estações de pastejo ao longo do processo de rebaixamento dos pastos. O mesmo autor relata que a maior presença de folhas no momento da entrada resultou nas maiores profundidades de desfolhação de perfilhos e nas maiores freqüências de desfolhação de folhas, principalmente no topo do dossel, resultado da maior acessibilidade das folhas ao pastejo, de forma que os animais não necessitaram, no início do pastejo, despender altos gastos de energia e tempo na busca por folhas, componente de maior valor nutritivo. No entanto, na medida em que o rebaixamento prosseguiu, as taxas de rebaixamento foram sendo reduzidas, as profundidades de desfolhação, massa do bocado e taxa de bocados diminuíram o que contribuiu para baixa taxa de consumo, além disso, a presença de colmos e material morto foram cada vez maiores nas proximidades do topo do dossel acarretando na redução da freqüência de desfolhação folhas.

Segundo Trindade (2007), a intensidade de pastejo menos severa, altura pós-pastejo $15 \mathrm{~cm}$, estiveram associadas com maior presença de folhas no topo do dossel nas fases finais do rebaixamento, resultando em maior proporção do tempo de ocupação dos piquetes sendo utilizada para a atividade de pastejo, maior taxa de bocados no final do rebaixamento, comparativamente à ruminação e outras atividades. Apesar de durante as fases iniciais do rebaixamento as massas do bocado, taxas de consumo e 


\section{INGESTÃO E DESLOCAMENTO DE BOVINOS}

intensidade de desfolhação de folhas em expansão e expandidas terem sido superiores para os tratamentos de altura pós-pastejo $10 \mathrm{~cm}$, os animais nesses tratamentos consumiram, durante os rebaixamentos, forragem com menor proporção de folhas, certamente porque o estrato pastejável foi maior e houve a necessidade de os animais aprofundarem a desfolhação até estratos onde havia maior quantidade de colmos e de material morto. Com relação às características estruturais dos pastos provenientes da duração da rebrotação, o autor inferiu que afetaram o comportamento dos animais, o consumo, seus padrões de deslocamento e busca por alimento e de desfolhação. Quando pastejaram pastos submetidos a períodos de rebrotação mais longos, apresentaram maior massa do bocado, em contrapartida, os bocados continham uma menor proporção de folhas e maior proporção de colmos e de material morto. Nesse cenário, os animais aumentaram o tempo gasto com ruminação e outras atividades e, ao longo do rebaixamento, aumentaram as frequências de trocas de estações alimentares e distância percorrida entre cada estação, possivelmente pela estrutura desfavorável que se formou nos pastos e onde o animal procedia à busca por alimento.

Avaliando os efeitos da densidade do caule dos pastos tropicais e a idade dos animais no seu comportamento de ingestivo em pastagens de Panicum maximum, Benvenutti et al. (2008) verificaram interação para a área do bocado, a massa de bocado e a taxa de ingestão instantânea. A densidade do caule teve um efeito negativo sobre essas variáveis que descrevem o comportamento ingestivo, particularmente maior para novilhos mais velhos. Os autores atribuíram a importância das hastes de alta elasticidade, resistindo como empecilhos do processo de pastejo em pastagens tropicais, especialmente em bovinos mais velhos.

\section{CONSIDERAÇÕESFINAIS}

Em escalas maiores, campo ou sítio, a decisão do animal no processo de pastejo se soma aos fatores bióticos e abióticos como topografia, disponibilidade de água, de abrigos. As refeições são divididas em turnos, podendo apresentar várias refeições que são interrompidas por intervalos de comprimento variado destinados a outras atividades, como caminhar, descansar ruminar. $\mathrm{O}$ animal responde diretamente à estrutura do pasto, obtendo uma velocidade de ingestão elevada quando a massa de forragem é adequada, enchendo rapidamente o rúmen, apresentando ciclos rápidos de saciedade e as refeições são mais numerosas e com longos intervalos, consequentemente maior o consumo.

Por ser o componente mais nutritivo e mais palatável, há uma preferência do animal pelas lâminas foliares, portanto as decisões do animal pela procura de forragem estão baseadas, preferencialmente na busca por este componente. Num cenário de alta oferta de forragem, especialmente maior relação lâmina:colmo e maior altura do dossel, o animal tende a aumentar o ângulo de deslocamento e aumento do tamanho e profundidade do bocado, o que resulta num maior tempo de permanência na mesma estação alimentar, no entanto, ocorre maior número de passos entre estações, em função da maior massa do último bocado, assim o animal se desloca enquanto a boca está cheia até a próxima estação. Numa situação inversa, pouca oferta de forragem, menor relação folha colmo, menor altura de dossel, diminui o tamanho e profundidade do bocado resultando em menor tempo de permanência dentro de cada estação, consequentemente maior número de estações visitadas até atingir a saciedade o que gera maior gasto de energia durante o deslocamento.

Embora as relações planta-animal interfiram na decisão do animal na busca pelo seu alimento na pastagem, o processo

Archivos de zootecnia vol. 59 (R), p. 67. 


\section{TEIXEIRA, MARQUES, SILVAE PIRES}

de pastejo, por outro lado, provoca mudanças na estrutura da planta, que por sua vez, fazem um feedback alterando os padrões de deslocamento, busca e apreensão do alimento, padrões de desfolhação de folhas e perfilhos durante o rebaixamento do pasto, como forma de tentar compensar reduções em taxa de consumo. Esses efeitos são mais pronunciados em pastagens tropicais que particularmente apresentam uma acentuada dureza e densidade das hastes se tornando um empecilho ao processo de pastejo pelo animal, especialmente, os mais velhos. Sob o ponto de vista

\section{BIBLIOGRAFIA}

Baggio, C., Carvalho, P.C.F. e Silva, J.L.S. 2008. Padrões de uso do tempo por novilhos em pastagem consorciada de azevém anual e aveiapreta. Rev. Bras. Zootecn., 37: 1912-1918.

Baggio, C., Carvalho, P.C.F., Silva, J.L.S., Anghinoni, I., Lopes, M.L.Te Thurow, J.M. 2009. Padrões de deslocamento e captura de forragem por novilhos em pastagem de azevém-anual e aveia-preta manejada sob diferentes alturas em sistema de integração lavoura-pecuária. Rev. Bras. Zootecn., 38: 215-222.

Bailey, D.W., Gross, J.E., Laca, E.A., Rittenhouse, R.L., Coughenour, M.B., Swift, D. and Sims, P.L. 1996. Mechanisms that result in large herbivore grazing distribution patterns. J. Range Manage., 49: 386-400.

Benvenutti, M.A., Gordon, I.J. and Poppi, D.P. 2008. The effects of stem density of tropical swards and age of grazing cattle on their foraging behaviour. Grass Forage Sci., 63: 1-8.

Brâncio, P.A., Euclides, V.P.B., Nascimento Junior, D., Fonseca, D.M., Almeida, R.G., Macedo, M.C.M e Barbosa, R.A. 2003. Avaliação de três cultivares de Panicum maximum Jacq. sob pastejo: comportamento ingestivo de bovinos. Rev. Bras. Zootecn., 32: 1045-1053.

Bremm, C., Rocha, M.G., Freitas, F.K., Macari, S., Elejalde, D.A.G. eRoso, D. 2008. Comportamento ingestivo de novilhas de corte submetidas a estratégias de suplementação em pastagens de aveia e azevém. Rev. Bras. Zootecn., 37: 1161-1167. animal, busca-se quantidade e valor nutritivo elevado, e, do ponto de vista da planta, menores frequências e intensidades de desfolhação em folhas permitem conduzir a uma estrutura com maior proporção de folhas tanto no pré como no pós-pastejo, assegurando a manutenção da produção e produtividade dos pastos. Seguramente, a grande importância e contribuição do entendimento destas relações, é o estabelecimento de estratégias de manejo visando criar ambientes adequados que favoreçam o consumo de forragem e a rebrotação rápida e vigorosa da planta.

Bullock, J.M. 1996. Plant competition and population dynamics. In: Hodgson, J., A.W. Illius (eds.). The ecology and management of grazing systems. CAB International. Wallingford. pp. 69-100.

Carvalho, P.C.F., Prache, S. e Damasceno, J.C. 1999. O Processo de pastejo: desafios da procura e apreensão da forragem pelo herbívoro. In: Penz Junior, A.M., L.O.B. Afonso, G.J. Wassermann (Org.). Reunião Anual da Sociedade Brasileira de Zootecnia. Anais... Porto Alegre, 1999. v. 36: 253-268.

Carvalho, P.C.F., Ribeiro Filho, H.M.N. ePoli, C.H.E.C 2001. Importância da estrutura da pastagem na ingestão e seleção de dietas pelo animal em pastejo. In: Mattos, W.R.S. (Org.). A produção animal na visão dos brasileiros. Reunião Anual da Sociedade Brasileira de Zootecnia, Anais... Piracicaba, 2001. v. 1: 853-871.

Carvalho, P.C.F. e Moraes, A. 2005. Comportamento ingestivo de ruminantes: bases para o manejo sustentável do pasto. In: Simpósio sobre Manejo Sustentável das Pastagens, 2005 Maringá. Anais... UEM. Maringá. 1 CD-ROM.

Carvalho, P.C.F., Trindade, J.K., Macari, S., Fisher, V., Poli, C.H.E.C. e Lang, C.R. 2007. Consumo de forragens por bovinos em pastejo. In: Simpósio sobre Manejo Sustentável das Pastagens, 24. 2007. Piracicaba. Produção de ruminantes em pastagens: anais. Fealq/USP. Piracicaba. pp. 177-218.

Flores, E.R., Laca, E.A., Griggs, T.C. and Demment, M.W. 1993. Sward height and vertical 


\section{INGESTÃO E DESLOCAMENTO DE BOVINOS}

morphological differentiation determine cattle bite dimensions. Agron. J., 85: 527-532.

Gibb, M. 1996. Animal grazing/intake terminology and definitions. In: Pasture ecology and animal intake, 3, 1996, Dublin. Proceedings... 21-37.

Gonçalves, E.N. 2007. Comportamento ingestivo de bovinos e ovinos em pastagem natural da depressão central do Rio Grande do Sul. Tese (Doutorado em Zootecnia). Faculdade de Agronomia. Universidade Federal do Rio Grande do Sul.

Gonçalves, E.N., Carvalho, P.C.F., Devincenzi, T., Lopes, M.L.T., Freitas, F.K. e Jacques, A.V.A. 2009. Relações planta-animal em ambiente pastoril heterogêneo: padrões de deslocamento e uso de estações alimentares. Rev. Bras. Zootecn., 38: 109-122.

Griffiths, W.M., Hodgson, J. and Arnold, G.C. 2003. The influence of sward canopy structure on foraging decisions by grazing cattle. I. Patch selection. Grass Forage Sci., 58: 112-124.

Hodgson, J. 1990. Grazing management: science into practice. John Willey. New York . 203 pp.

Illius, A.W. and Gordon, I.J. 1999. The physiological ecology of mammalian herbivory. In: Jung, H.J.G., Fahey Jr., G.C. (eds.). Nutritional ecology of herbivores. International Symposium on the nutrition of herbivores, 5. San Antonio. USA Proceedings ... pp. 71-96.

Ítavo, L.C.V., Souza, S.R.M.B.O., Rímoli, J., Ítavo, C.C.B.F. e Dias, A.M. 2008. Comportamento ingestivo diurno de bovinos em pastejo contínuo e rotacionado. Arch. Zootec., 57: 43-52.

Launchbaugh, K.L. and Howery, L.D. 2005. Understanding landscape use patterns of livestock as a consequence of foraging behavior. Rangeland Ecol. Manag., 58: 99-108.

Manzano, R.P., Nussio, L.G., Campos, F.P., Andreucci, M.P. e Costa. 2007. Comportamento ingestivo de novilhos sob suplementação em pastagens de capim-tanzânia sob diferentes intensidades de desfolhação. Rev. Bras. Zootecn., 36: 550-557.

Olivo, C.J., Ziech, M.F., Meinerz, G.R., Both, J.F., Agnolin, C.A. e Vendrame, T. 2008. Comportamento ingestivo de vacas em lactação em diferentes sistemas forrageiros. Rev. Bras. Zootecn., 37: 2017-2023.

Palhano, A.L., Carvalho, P.C.F., Dittrich, J.R., Moraes, A., Silva, S.C. e Monteiro, A.L.G. 2006.
Padrões de deslocamento e procura por forragem de novilhas leiteiras em pastagem de capim-mombaça. Rev. Bras. Zootecn., 35: 22532259.

Páscoa, A.G. e Paranhos da Costa, M.J.R. 2007. Aplicação dos sistemas de informação geográfica para definição de estratégias de manejo de bovinos nas pastagens. Rev. Bras. Zootecn. (suplemento especial), 36: 45-51.

Penning, P.D., Parsons, A.J, Orr, R.J. and Treacher, T.T. 1991. Treacher Intake and behaviour responses by sheep to changes in sward characteristics under continuous stocking. Grass Forage Sci., 46: 15-28.

Prache, S. et Peyraud, J.L. 1997. Préhensibilité de l'herbe pâturée chez lez bovins et les ovins. INRA Production Animales, 10: 377-390.

Rego, F.C.A., Damasceno, J.C., Fukumoto, N.M., Côrtes, C., Hoeshi, L., Martins, E.N. e Cecato, U. 2006. Comportamento ingestivo de novilhos mestiços em pastagens tropicais manejadas em diferentes alturas. Rev. Bras. Zootecn. (supl.), 35: 1611-1620.

Roguet, C., Dumont, B. and Prache, S. 1998 Selection and use of feeding sites and feeding stations by herbivores: a review. Ann. Zootech., 47: 225-244.

Roman, J., Rocha, M.G., Genro, T.C.M., Santos, D.T., Freitas, F.K. e Montagner, D.B. 2008. Características produtivas e estruturais do milheto e sua relação com o ganho de peso de bezerras sob suplementação alimentar. Rev. Bras. Zootecn., 37: 205-211.

Rook, A.J. and Penning, P.D. 1991. Synchronization of eating, ruminating and idling activity of grazing sheep. Appl. Anim. Behav. Sci., 32: 157-166.

Ruyle, G.B. and Dwyer, D.D. 1985. Feeding stations of sheep as an indicator of diminished forage supply. J. Anim. Sci., 61: 349-353.

Sbrissia, A.F., Da Silva, S.C., Matthew, C., Carvalho, C.A.B., Carnevalli, R.A., Pinto, L.F.M., Fagundes, J.L. and Pedreira, C.G.S. 2003. Tiller size/density compensation in grazed Tifton 85 bermudagrass swards. Pesq. Agropec. Bras., 38: 1459-1468.

Sbrissia, A.F. 2004. Morfogênese, dinâmica do perfilhamento e do acúmulo de forragem em pastos de capim-Marandu sob lotação contínua 2004. Tese (Doutorado em Ciência Animal e Pastagens). Escola Superior de Agricultura Luiz de Queiroz. Universidade de São Paulo. 


\section{TEIXEIRA, MARQUES, SILVAE PIRES}

Piracicaba. $171 \mathrm{pp}$

Silva, S.C. and Carvalho, P.C.F. 2005. Foraging behaviour and intake in the favourable tropics/ sub-tropics. In: McGilloway, D.A. (Ed.) Grassland: a global resource. Wageningen Academic Publishers. Wageningen. pp. 81-95. Silveira, E.O. 2001. Produção e comportamento ingestivo de cordeiros em pastagem de azevém anual (Lolium multiflorum Lam.) manejado a diferentes alturas. Dissertação (Mestrado em Zootecnia). Faculdade de Agronomia. Universidade Federal do Rio Grande do Sul.

Teixeira, F.A. 2010.Diferimento de pastagem de Brachiaria decumbens e estratégias de adubação nitrogenada. Tese-Doutorado em Zootecnia (Área de Concentração em Produção de Ruminantes). UESB. Itapetinga-BA. 149 pp. Trindade, J.K. 2007. Modificações na estrutura do pasto e no comportamento ingestivo de bovinos durante o rebaixamento do capim marandu submetido a estratégias de pastejo rotacionado. Dissertação (Mestrado em Agronomia). Escola Superior de Agricultura Luiz de Queiroz. Faculdade de Agronomia. Piracicaba-SP.

Ungar, E.D., Genizi, A. and Demment, M.W. 1991. Bite dimensions and herbage intake by cattle grazing short hand constructes swards. Agron. J., 83: 973-978.

Archivos de zootecnia vol. 59 (R), p. 70. 